\title{
Cultural stereotypes in care contexts
}

This article was published in the following Dove Press journal:

Clinical Interventions in Aging

\author{
Rocío Fernández- \\ Ballesteros' \\ Macarena Sánchez- \\ Izquierdo² \\ Ricardo Olmos ${ }^{3}$ \\ Carmen Huici ${ }^{4}$ \\ Marta Santacreu ${ }^{5}$ \\ Rocío Schettini ${ }^{6}$ \\ María Ángeles Molina ${ }^{6}$ \\ 'Department of Psychobiology and \\ Health, Autonomous University of \\ Madrid, Madrid, Spain; ${ }^{2}$ Department \\ of Psychology, Universidad Pontificia \\ Comillas, Madrid, Spain; ${ }^{3}$ Department \\ of Methodology, Autonomous \\ University of Madrid, Madrid, \\ Spain; ${ }^{4}$ Department of Social and \\ Organizations Psychology, Universidad \\ Nacional de Educación a Distancia, \\ Madrid, Spain; ${ }^{5}$ Department of \\ Psychology, Universidad Europea, \\ Madrid, Spain; ${ }^{6}$ Department of \\ Psychology, Universidad Francisco de \\ Vitoria, Madrid, Spain
}

Introduction: The main goal of the present study was to examine the stereotype content model (SCM) assumption for universality and to test whether the mediating role of cultural views about older adult caregivers is maintained in other health care contexts.

Methods: One hundred and sixty professionals and volunteers who worked with older adults in day care centers (DCCs) and senior citizen centers (SCCs) and 1,151 participants from a representative sample of the Spanish population were examined using the SCM questionnaire; older adult and personnel functioning were assessed through an observation procedure with two subscales of the Evaluation Scale from the Sistema de Evaluación de Residencias de Ancianos.

Results: The results showed that the context does not seem to influence the cultural views about older adults held by caregivers. All results support the cultural stereotype pattern in which members of the older adult group are viewed with high warmth (HW) and low competence (LC) as posited by the SCM model. With respect to the mediation of cultural stereotypes on caregivers/older adult functioning, this has not been supported in this study. Neither cultural views of warmth (predicted by the SCM) nor views of competence (from our previous studies) influence either caregiver functional behaviors or older adult functioning.

Conclusion: Two post hoc hypotheses can be inferred: 1) there is more variability in competence and warmth in DCCs and SCCs and 2) although we did not find significant differences in the pattern of competence and warmth in perceived cultural stereotypes about older adults, more healthy environments could reduce the influence of cognitive views on behavior.

Keywords: caregiving, prejudice, cultural stereotypes, caregiver functioning, older adult functioning

\section{Introduction}

The present study extends our previous work on ageism in the domain of health care and, more specifically, on the potential effects of cultural stereotypes about older adults held by caregivers and how these stereotypes affect their behaviors toward older adults. The study tries to show how these cultural stereotypes may be mediators between caregiver behaviors and older patient functioning. It draws on the stereotype content model (SCM), which proposes that cultural beliefs about social groups (that is, how groups are perceived in a given social context) can be classified into two basic dimensions: 1) competence, consisting of characteristics such as intelligence, independence, being successful, etc. and2) warmth, the groups traits of which imply friendliness, kindness, tolerance, etc. According to the authors, these basic dimensions in turn relate to structural relationships such as the relative competence between the groups and their relative status in society. The model also links the content of cultural stereotypes about a group to specific combinations of warmth and competence attributed to the group.

A broad worldwide research program by Fiske et al $^{1}$ yielded several profiles of high versus low combinations of warmth and competence. A new and more integrative model, BIAS, was developed to relate stereotype profiles not only to emotional prejudice but also to behavioral reactions toward the groups. The emotions considered

\author{
Correspondence: Rocío Fernández- \\ esteros \\ Universidad Autónoma de Madrid, \\ Ciudad Universitaria de Cantoblanco, \\ C/lván Pavlov, 6, 28049, Madrid, Spain \\ Tel +34 9l 4975181 \\ Fax +34 91 4975215 \\ Email r.fballesteros@uam.es
}

Clinical Interventions in Aging 2018:13 1613-1619

Dovepress in 0

http://dx.doi.org/1 0.2147/CIA.S169487 (c) (1) (8) 2018 Fernández-Ballesteros et al. This work is published and licensed by Dove Medical Press limited. The full terms of this license are available at https://www.dovepress.com/terms.php (c) ${ }_{\mathrm{BY}} \mathrm{NC}$ and incorporate the Creative Commons Attribution - Non Commercial (unported, v3.0) License (http://creativecommons.org/licenses/by-nc/3.0/). By accessing the work you hereby accept the Terms. Non-commercial uses of the work are permitted without any further permission from Dove Medical Press Limited, provided the work is properly attributed. For permission for commercial use of this work, please see paragraphs 4.2 and 5 of our Terms (https://www.dovepress.com/terms.php). 
were admiration, envy, pity and contempt, which correspond to the stereotype profiles. ${ }^{2}$ In relation to behavioral reactions, the BIAS model posited assumptions about the relationships between stereotypes and behavior. From this perspective, the two stereotype patterns, low/high competence and warmth, would be related to four classes of behaviors, crossing active versus passive behaviors with facilitation versus harm: 1) active facilitation (active for) includes helping, assisting or defending interpersonal behaviors; 2) active harm (acting against) includes discriminatory behavior; 3 ) passive facilitation (acting with) includes obligatory association or cooperation with the group; 4) passive harm (acting without) demeans or distances other groups by diminishing their social worth through excluding, ignoring or neglecting.

In the case of the older adult group, research based on the model consistently shows that members are placed in the low-competence (LC)/high-warmth (HW) cluster. In a large international study, participants in all the samples viewed elderly people as significantly more warm than competent. ${ }^{3}$ To this stereotypical cognitive dimension, the SCM added an emotional one reflecting an ambivalent paternalistic prejudice, that is, feelings of pity and sympathy, and to a lesser degree admiration. ${ }^{2}$ As the authors point out, pity, the main emotion uniquely directed to this group, may seem positive on the surface but it may involve a view of older people as helpless and may promote their dependence through paternalistic behaviors.

In relation to behaviors, $\mathrm{HW}$ should promote active facilitation such as helping, and LC favors passive harm such as neglecting or excluding. In their extensive research stemming from their BIAS model, which includes stereotypes, affective reactions and behaviors, authors were able to support the basic tenets of the model. Regarding groups stereotyped as low on competence but high on warmth, they found that they elicited pity and active facilitation but passive harm. ${ }^{4}$ Cuddy et $\mathrm{al}^{3}$ described the ambivalent pattern of behavior that may be expected in the case of the elderly: being helped but also risking neglect and disregard. They stress the importance of this pattern of behavior in different domains and in particular medical settings and on physician-older patient communication, such as showing less engagement and respect toward older compared to younger patients. ${ }^{5}$

It must be emphasized that the samples used in the SCM mostly comprised university students, although SCM authors never tested both types of hypotheses from the stereotypical model or their relationships with behavior within older adult care contexts. We are therefore attempting to investigate the extent to which hypotheses originating from this model could be tested in older adult contexts.

Since 2012, our research unit Aging and AssessmentEVE group has been trying to test some of the theoretical assumptions in several care contexts in Mexico and Spain. ${ }^{6-10}$ Results have supported SCM assumptions regarding the stereotypical components of the model. Using a sample of the Spanish Society of Geriatrics and Gerontology (SEGG) ${ }^{6}$ in care contexts assessed in Mexico, ${ }^{7,8}$ Nursing Homes in the Basque Country, Spain, ${ }^{9}$ in the University Program for Older Adults, ${ }^{10}$ older adult cultural stereotypes reported by professional caregivers working with older adults confirm the model: older adults are significantly perceived as having lower competence than warmth (SEGG: mean SEGG members reported warmth $=4.81$ and competence $=4.39[t(324)=$ 8.65, $p<0.001]$; Mexico: mean warmth $=3.59$ and competence $=2.91[t(116)=9.989, p<0.001]$; Spain-Basque Country: mean warmth $=3.57$ and competence $=2.91$ ) (although the response format in all contexts was a 7-point Likert scale, we reduced this to 5 in order to fit the SCM metric).

This study also included behaviors of both caregivers and older adults in the different care contexts. The basic function of caregiver behavior has to do not only with active facilitation but also with respect for the individual, that is, in BIAS model dimensions, avoiding passive harm aspects that may diminish their social worth, while also acknowledging their independence.

Caregiver and older adult functioning were observed through the RS (Rating Scale; staff functioning and residents' functioning)-SERA (Sistema de Evaluación de Residencias de Ancianos [Assessment System for older Adults Residences] $)^{11}$ within the nursing homes. One of the main findings was that caregivers' views about older adult competence mediate better functioning both in professional caregivers (promoting older adult independence) and in older adult clients (performing better functioning). It appears that cultural stereotypes predict caregiver behaviors (caregiver functioning), and it was higher competence (not warmth), which predicted associations between caregiver stereotypes (cultural views about older adult competence) and overt behavior assessed through direct observation, that is, competence perception elicits active facilitating behaviors in caregivers and also mediates higher older adult functioning, thereby benefiting the group as predicted.

In sum, caregivers' cultural views of older adults at present fit the SCM model in line with the assumption of "universality"; ${ }^{1}$ however, perceived competence but not warmth mediates active facilitation of caregiver behaviors. 
Nevertheless, in most of the caregiving contexts assessed, highly impaired older adults were prevalent; thus, we continue to be interested in testing both assumptions, SCM universality and competence/warmth behavioral mediation, in more "normalized" older adult contexts.

In this paper, we have hypothesized that the SCM would fit other older adult contexts, such as day care centers (DCCs), senior citizen centers (SCCs) and even a representative sample of the Spanish population. Also, our wish to test the hypothesis regarding the mediating role of cultural views of older adult caregivers is maintained in healthier contexts, investigating whether cultural stereotypes mediate caregivers' functioning.

\section{Materials and methods}

A two-step cross-sectional design based on both self-report measures and observational analyses was approved by the Ethics Committee of Autonoma University of Madrid (November 2014) and subsequently administered in this study.

\section{Participants}

Professionals and volunteers who worked with older adults in two contexts $(\mathrm{N}=162)$ and a representative sample of the Spanish population $(\mathrm{N}=1,151)$ participated in this study, resulting in a response rate of $57 \%$.

1. SCCs are community focal points offering a wide variety of educational and leisure programs and services to connect older adults and help them to remain healthy and independent. Sixteen SCCs administered by Madrid City Hall volunteered to participate. From these centers, 92 caregivers and trainers participated in the study (program professionals were recruited trainers, and volunteers were retired adults who offered their expertize in teaching courses without payment): 24 were staff members and 64 were volunteer trainers (mean age $=54.12$ years, $\mathrm{SD}=17.53$, age range $=22-85$ years; $53.2 \%$ women); they did not differ significantly in their views of older adults. Regarding their professions, most of them (60.3\%) were health professionals (geriatricians, psychologists, occupational therapists, physiotherapists) and $40 \%$ had other professions (teacher, electronics experts, technician, etc.); no differences were found among them in their stereotypical views. Finally, mean years spent working with older adults were as follows: full-time staff $=9.47$ years, $\mathrm{SD}=$ 8.35 and volunteers $=9.06$ years, $\mathrm{SD}=7.61$.

2. Adult DCCs provide health, cognitive and social services to older adults with some degree of physical, cognitive or mobility impairment who require skilled nursing care or therapy services for rehabilitation purposes. Six public DCCs in Madrid city, one public DCC in neighboring Alcobendas and six private DCCs in Madrid city belonging to Asociación Servicio Integral Sectorial Para Ancianos (ASISPA) (a non-profit private association whose mission is to carry out activities promoting independence as well as to provide the best possible service for senior adults) agreed to participate in this study. From these 13 centers, a sample was composed of 70 professionals (mean age $=43.36$ years, $\mathrm{SD}=11.66$; $53.7 \%$ women) with the following professions: one doctor, four nurses, three assistants in geriatrics, five psychologists, 10 social workers, 42 other medical professionals (eg, occupational therapists, physiotherapists, speech therapists), five others (eg, catering industry, transport assistants). Mean years spent caring for older adults was 11.58 years. $(\mathrm{SD}=7.52)$.

3. Representative Random Sample (RRS) consisting of 1,151 participants representative in terms of age (over 15) and sex was recruited from all Spanish regions using a random route procedure, with a mean age of 46.69 years, $\mathrm{SD}=18.20 ; 52 \%$ were women.

\section{Measures}

The SCM questionnaire ${ }^{2}$ was anonymously administered to all caregivers once they had provided written informed consent. The same instrument was administered to a representative sample of the Spanish population. The questionnaire was composed of two subscales: competence and warmth. All participants read or were informed about the following instructions:

"Here, you can read a set of characteristics defining people.

We are not interested in your personal opinion, only in the extent to which you think these characteristics define young and older people in Spain".

Response format was a 7-point Likert scale (from "Describes them perfectly to Does not describe them at all"; for data analysis, the 7 points were reduced to 5 in order to fit the SCM metric). Following Fiske et al, ${ }^{2}$ the mean values of competence and warmth were compared in the three groups to investigate the stereotypical LC/HW pattern. Reliability of the two subscales was as follows: $\alpha=0.870$ for the competence scale and $\alpha=0.820$ for the warmth scale.

In order to observe the two types of care contexts, two subscales of the Evaluation Scale from SERA ${ }^{11}$ (adapted from the Multiphasic Environmental Assessment Procedure ${ }^{12}$ ) were administered in 16 SCCs and 13 Adult DCCs. Response options in both subscales range from 0 to 3 , with higher 
scores indicating good/bad functioning of older adults or personnel.

1. Older adult functioning scale includes five dimensions: personal grooming, condition of clothing, older adult interaction, brief verbal exchanges and general activity level $(\alpha=0.787)$.

2. Personnel functioning scale includes five dimensions: quality of interaction, physical contact with older adults, organization, caregiver availability for older adults (users or residents) and caregiver conflict ( $\alpha=0.733$ ).

\section{Observation procedure}

Both the SERA manual ${ }^{11}$ and a standardization study ${ }^{13}$ reported high inter-observer agreement (personnel $=0.710$, users $=0.770)$. In the preparatory study, the intra-class correlation index (ICC) was computed (assuming a random effect for the two trained raters as well as for the different centers) to estimate inter-rater reliability. In this study, the standard procedure was for a trained observer to observe all communal areas in a total of 29 centers (19 DCCs and $13 \mathrm{SCCs}$ ) for two sessions (morning/afternoon) for 45 minutes per session. The observation scales were normally assessed after the observation period. The observer only registered caregiver and older adult functioning evident during the observational period. The observer was never aware of whether personnel members had completed the SCM questionnaire or not.

\section{Data analysis}

In order to evaluate the extent to which predictive stereotype patterns (LC and HW) are care-context dependent, a two-way mixed analysis of variance (ANOVA) was conducted with SPSS software (version 24). The dependent variable was the individual scores in the SCM questionnaire.

Also, to examine the predicted mediational model, Mplus structural equation modeling software was used, version 7.0. ${ }^{14}$ In the mediational model, the dependent variable was RSSERA (the average score of the two raters in each center). The independent variable was SERA personnel functioning (also averaged by the two raters); the mediational variables were the aggregated SCM questionnaire caregiver scores in the observed centers. The estimation method was maximum likelihood. A total of $\mathrm{N}=29$ centers were analyzed in this mediational model. The $\chi^{2}$ statistic was used as a goodnessof-fit index.

\section{Results}

To study the extent to which stereotype patterns (LC and HW) are care-context dependent, a two-way mixed ANOVA was performed where the within-subject factor was the subscale (competence and warmth) and the between-subject factor was the context (the context was represented by three groups: DCC, SCC and RRS). The dependent variable was the scores in competence and warmth from the SCM questionnaire. Box's $M$ test of homogeneity of variance-covariance matrices between the three groups was supported (Box's $M$ test $=7.899, p=0.251)$. Table 1 shows the descriptive statistics of all the assessed conditions.

The factor effect between contexts was significant: $F(2,1142)=91.145, p<0.001, \eta^{2}=0.138$; thus, the effect size was high. ${ }^{15}$ The post hoc comparison showed that RRS obtained a higher mean than the other two caregiver groups $(p<0.001)$. There was no difference between the SCC group and the Adult Day Health Care Center group ( $p=0.427)$. The within-subject main effect of the subscale was also significant: $F(1.1142)=96.725, p<0.001, \eta^{2}=0.078$. In particular, a stereotype pattern ( $\mathrm{LC}$ and $\mathrm{HW}$ ) is present in all contexts: in the SCC group, caregivers rated warmth $($ mean $=3.205)$ higher than competence $($ mean $=2.815)$, $p<0.001$; in the Adult Day Health Care Center group, the pattern was similar. They rated warmth $($ mean $=3.380)$ higher than competence $($ mean $=2.906), p<0.001$. Finally, the same pattern was found in the representative Spanish sample, where the warmth dimension was rated higher $($ mean $=3.972)$ than competence $($ mean $=3.696), p<0.001$; moreover, no significant differences by sex were found in this pattern (neither in views of competence nor warmth), nor were significant differences found in competence attribution by age, but age was significantly related to the view of warmth, and this increased with age $[F(5,983)=7.818, p<0.001]$.

Figure 1 shows the results of the two-way ANOVA. In sum, cultural views of older adults held by caregivers in different care contexts, including a representative sample of Spanish population, support the stereotype pattern HW and LC posited by Fiske et al in the SCM model, ${ }^{2,16}$ endorsing our previous studies in care contexts. ${ }^{8,17}$

Second, in order to check whether stereotypes mediate caring, mediational analysis was conducted (see Table 2).

Table I Views held by caregivers in DCCs and SCCs and in a representative sample of the Spanish population about competence and warmth

\begin{tabular}{llll}
\hline & $\begin{array}{l}\text { DCCs } \\
(\mathbf{N}=\mathbf{6 8})\end{array}$ & $\begin{array}{l}\text { SCCs } \\
\mathbf{( N = 8 8 )}\end{array}$ & $\begin{array}{l}\text { RRS } \\
(\mathbf{N}=\mathbf{9 8 9})\end{array}$ \\
\hline Competence, mean \pm SD & $2.91 \pm 0.82$ & $2.82 \pm 0.8 \mathrm{I}$ & $3.58 \pm 0.8 \mathrm{I}$ \\
Warmth, mean \pm SD & $3.38 \pm 0.75$ & $3.21 \pm 0.86$ & $3.88 \pm 0.78$ \\
\hline
\end{tabular}

Abbreviations: DCC, day care center; SCC, senior citizen center; RRS, representative random sample. 


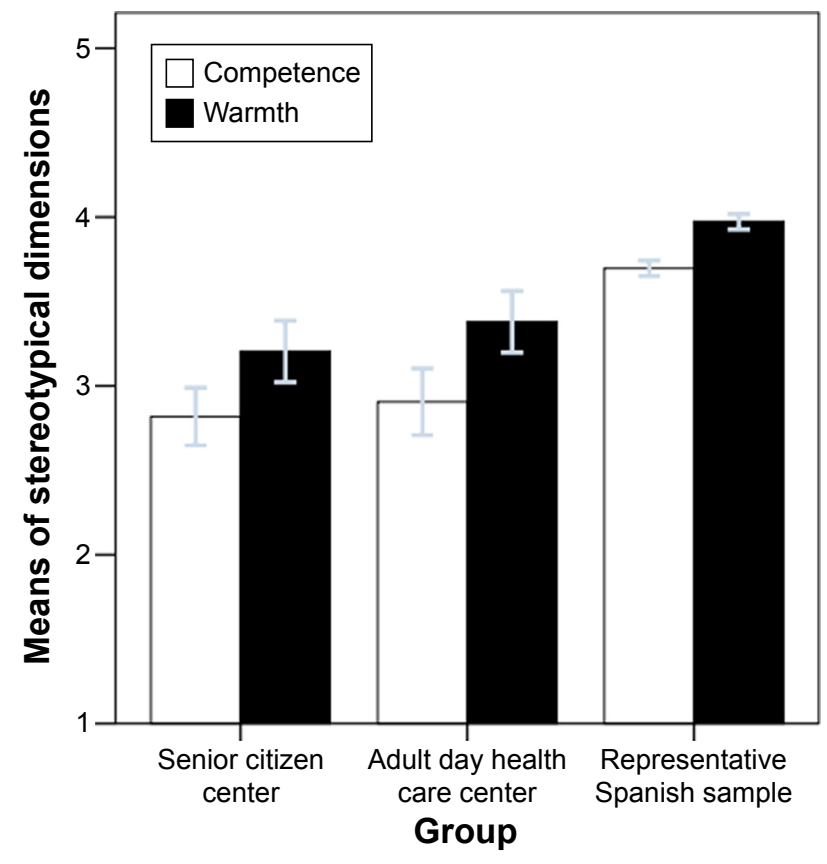

Figure I Mean and error bars (95\%) for the two subscales in the three groups.

As mentioned in the method section, ICC was computed for the center level variables: for the user functioning scale, the mean reliability ICC was 0.697 and for the personnel functioning scale ICC was 0.710 . No extreme values were found, although for personnel functioning and user functioning, non-normal distributions were found $(K-S=0.232, p<0.001$ for personnel functioning and $K-S=0.324, p<0.001$ for user functioning).

In this model, personnel functioning (exogenous variable) has a direct effect on perceived competence and warmth (mediational variables) and an indirect effect on user functioning (dependent variable). Figure 2 represents the mediational model tested.

The model fits the data well: $\chi^{2}(1)=0.978, p=0.323$. Figure 2 also shows the completely standardized coefficients and their $p$-values. None of the studied effects were statistically significant $(p>0.05)$; thus, it cannot be concluded that a mediational (or a direct) effect exists. The Pearson

Table 2 Pearson correlations for center variables in the mediational analysis $(\mathrm{N}=29)$

\begin{tabular}{llll}
\hline & $\begin{array}{l}\text { Older } \\
\text { adults } \\
\text { functioning }\end{array}$ & Competence Warmth \\
\hline Personnel functioning & 0.214 (ns) & -0.052 (ns) & -0.025 (ns) \\
Older adults functioning & -0.220 (ns) & $-0.198(\mathrm{~ns})$ \\
Competence & & $0.579(p<0.00 \mathrm{I})$ \\
\hline
\end{tabular}

Abbreviation: ns, non-significant correlation. correlations used to explore the model are presented in Table 2. In sum, results are not congruent with our previous studies in older adult residential care contexts, ${ }^{8,17}$ showing that cultural views of older adults regarding competence/ warmth could moderate the effects of caregiver performance on older adult functioning, which were based on the SCM assumption of Cuddy et $\mathrm{al}^{4}$ that cultural stereotypes could mediate behavioral functioning. Our post hoc explanatory hypothesis is that this could be due to the contextual type of care of our previous and present type of care; however, new studies are needed to test this post hoc assumption.

\section{Discussion}

Both professional and volunteer caregivers working in DCCs and SCCs, compared with a representative sample of the Spanish population, hold stereotypical cultural views of older adults, attributing LC and HW to them. These results replicate those found in our studies in Mexico ${ }^{7,8}$ and in Nursing Homes in the Basque Country and in a sample of Spanish Gerontologists and Geriatricians, ${ }^{6,9}$ as well as those obtained by Fiske et $\mathrm{al}^{2}$ and Cuddy et $\mathrm{al}^{4}$ in university students in the USA and in six other countries in Europe (Belgium, Israel), Latin America (Costa Rica) and Asia (South Korea, Japan and Hong Kong).

Nevertheless, we can also state that all our caregiver samples yielded lower cultural stereotype profiles of the older adults group than those reported by Fiske et $\mathrm{al}^{2}$ (competence $=2.74$ and warmth $=4.6$ ). Values in competence in all our studies range from 2.91 (in Mexico) to 2.81 in SCCs and scores in warmth range from 3.59 (in Mexico) to 3.20 (in SCCs). Similarly, the representative Spanish sample yielded significantly different scores: competence $=3.70$ and warmth $=3.97$. Table 3 shows a summary of all scores in competence and warmth throughout our studies on this subject population.

In sum, as suggested by the SCM, the context does not seem to influence the cultural views of older adults held by caregivers, including a general context such as a representative sample of the Spanish population. All results support the cultural stereotype pattern in which the older adult group is viewed with $\mathrm{HW}$ and LC, as posited by Fiske et $\mathrm{al}^{2,16}$ from the SCM, which also supports our previous studies in care contexts. ${ }^{8,9}$

With respect to the mediation of cultural stereotypes on behavior predicted on the basis of the BIAS model, ${ }^{4}$ which has already been borne out in several studies conducted by our research group, ${ }^{7-9,18}$ results showing that caregivers' cultural views of older adults mediated the relationship of 


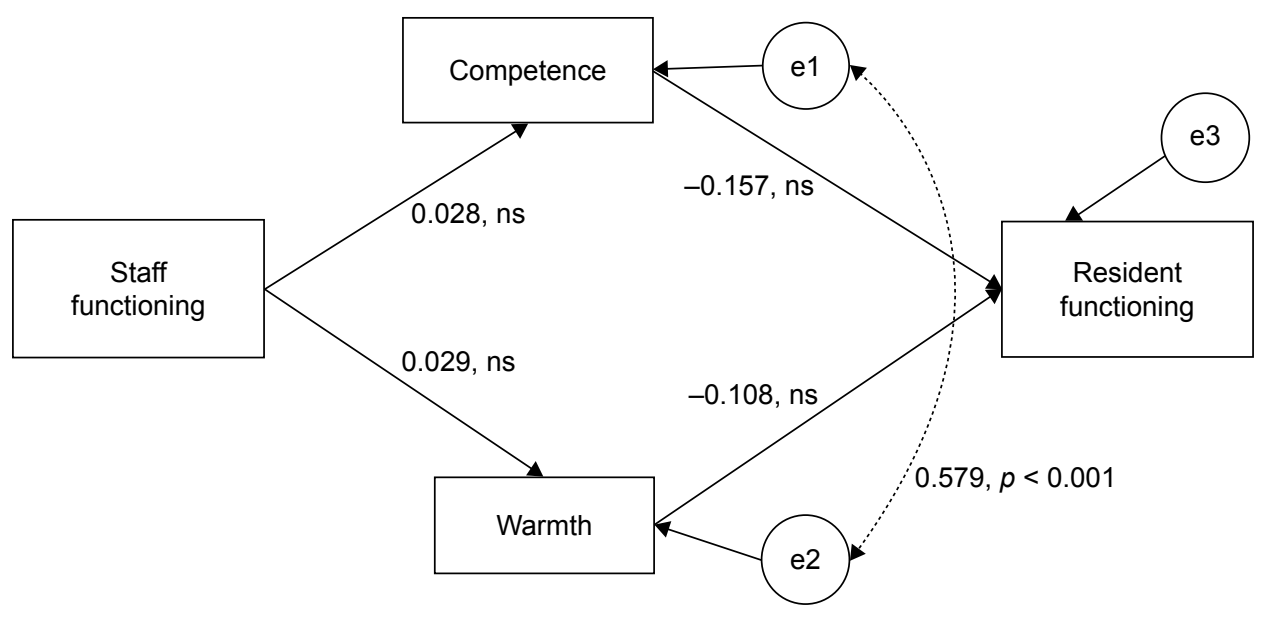

Figure 2 Mediation analysis.

Abbreviations: e, error variance; ns, non-significant.

caregivers/older adult functioning, in the sense that caregiver functioning actively facilitated older adult functioning, have not been supported in this study, despite the LC/HW pattern being preserved. Neither cultural views of warmth (predicted by the SCM) nor views of competence (from our previous studies) influence either caregiver functional behaviors or older adult functioning. Two post hoc hypotheses can be inferred: 1) there is more variability in competence and warmth in DCCs and SCCs and 2) although we did not find significant differences in the pattern of competence and warmth in perceived cultural stereotypes about older adults, more healthy environments could reduce the influence of cognitive views on behavior. More research should be conducted in order to offer any positive or negative response regarding the relationships of stereotypes and behaviors.

This study has several limitations resulting from a combination of ethical norms and our attempt to avoid bias. First of all, $43 \%$ of professionals and volunteers who work in the centers failed to respond, which may lead to a loss of accuracy in population estimates. Individuals are more inclined to participate when they find the research topic important to their lives or when they are highly involved in caregiving, ${ }^{19}$ Sixty-nine per cent of respondents in SCCs are volunteers and therefore dedicate some of their free time to helping old people, and although it is an enriching activity, it might not be central to their lives; consequently they may not have felt the need to complete the questionnaire.

Secondly, although we assess caregivers' self-reported views of older adults anonymously, and the caregivers and observers of older adult functioning in daily life within the center are blind to caregivers' reported cultural stereotypes, it is possible that the observed caregivers may not be maintaining the normal pattern of self-reported views (high competence/low warmth). Thus, we also assessed several subjects (caregivers and older adults) using different methods (self-reports and observation), and this data-gathering procedure reduces result consistency. Moreover, given their different sources of bias, the combination of self-reported cognitive behavior and direct observation of motor behaviors increases sources of variation. In sum, much more research

Table 3 Summary of all studies performed on cultural views about older adults

\begin{tabular}{|c|c|c|c|c|c|c|c|c|}
\hline \multirow[t]{2}{*}{$\begin{array}{l}\text { Cultural } \\
\text { stereotypes }\end{array}$} & \multirow[t]{2}{*}{$\begin{array}{l}\text { Older adults } \\
\text { contexts in } \\
\text { Mexico }^{7,8}\end{array}$} & \multicolumn{2}{|c|}{$\begin{array}{l}\text { Nursing } \\
\text { homes } \\
\text { Basque } \\
\text { country9 }\end{array}$} & \multirow[t]{2}{*}{$\begin{array}{l}\text { Day care } \\
\text { centers }\end{array}$} & \multirow[t]{2}{*}{$\begin{array}{l}\text { Older adults } \\
\text { centers }\end{array}$} & \multirow[t]{2}{*}{$\begin{array}{l}\text { Representative } \\
\text { sample }\end{array}$} & \multirow[t]{2}{*}{$\begin{array}{l}\text { University } \\
\text { older adults } \\
\text { programs }\end{array}$} & \multirow[t]{2}{*}{$\begin{array}{l}\text { SEGG } \\
\text { members }\end{array}$} \\
\hline & & $\begin{array}{l}\text { SC } \\
\text { units }\end{array}$ & $\begin{array}{l}\text { PCC } \\
\text { units }\end{array}$ & & & & & \\
\hline Competence (I-5) & $2.91 \pm 0.71$ & \multicolumn{2}{|c|}{$2.91 \pm 0.69$} & $2.88 \pm 0.82$ & $2.8 I \pm 0.8 I$ & $3.70 \pm 0.75$ & $3.47 \pm 0.60$ & $3.26 \pm 0.63$ \\
\hline Warmth (I-5) & $3.59 \pm 0.66$ & \multicolumn{2}{|c|}{$3.57 \pm 0.64$} & $3.38 \pm 0.75$ & $3.20 \pm 0.86$ & $3.97 \pm 0.73$ & $3.59 \pm 0.67$ & $3.54 \pm 0.62$ \\
\hline $\begin{array}{l}\text { Paired } t \text {-test and } \\
\text { probability }\end{array}$ & $\begin{array}{l}t(116)=9.989 \\
p<0.00 I\end{array}$ & \multicolumn{2}{|c|}{$\begin{array}{l}t(1 \mid 6)=9.989 \\
p<0.001\end{array}$} & $\begin{array}{l}t(67)=5.447 \\
p<0.001\end{array}$ & $\begin{array}{c}t(87)=5.501 \\
p<0.00 I\end{array}$ & $\begin{array}{l}t(988)=12.299 \\
p<0.00 I\end{array}$ & $\begin{array}{l}t(I 20)=2.709 \\
p=0.008\end{array}$ & $\begin{array}{l}t(324)=8.653 \\
p<0.00 I\end{array}$ \\
\hline
\end{tabular}

Note: Data shown as mean and SD in all studies performed.

Abbreviations: PCC, person-centered care; SC, standard care; SEGG, Spanish Society of Geriatrics and Gerontology. 
is required combining subjects and methods while reducing uncertainty and preserving ethics.

\section{Acknowledgment}

This study received a grant from MINECO: Project PSSI2014-5264-PICESEN.

\section{Disclosure}

The authors report no conflicts of interest in this work.

\section{References}

1. Fiske ST, Cuddy AJ, Glick P. Universal dimensions of social cognition: warmth and competence. Trends Cogn Sci. 2007;11(2):77-83.

2. Fiske ST, Cuddy AGC, Glick P, Xu J. A model of (often mixed) stereotype content: competence and warmth respectively follow from perceive status and competition. J Personal Soc Psychol. 2002;82(6):878-902.

3. Cuddy AJC, Norton MI, Fiske ST. This old stereotype: the pervasiveness and persistence of the elderly stereotype. J Soc Issues. 2005;61:265-283.

4. Cuddy AJ, Fiske ST, Glick P. The BIAS map: behaviors from intergroup affect and stereotypes. J Pers Soc Psychol. 2007;2(4):631-648.

5. Greene MG, Adelman RD, Charon R, Friedman E. Concordance between physicians and their older and younger patients in the primary care medical encounter. Gerontologist. 1989;29(6):808-813.

6. Fernández-Ballesteros R, Bustillos A, Santacreu M, et al. Assessing Ageing Stereotypes. 12th European Conference of Psychological Assessment. July 10-17, 2013; San Sebastian.

7. Bustillos A, Fernández-Ballesteros R. Efectos de los estereotipos del personal de atención a adultos mayores del Estado de Colima [Effect of stereotypes about old age in the care of older adults from the State of Colima]. Rev Mex Salud Pública. 2012;2:104-105. Spanish.
8. Bustillos A, Fernández-Ballesteros R. Is older adults' functioning affected by stereotypes held by caregivers? GeroPsyc. 2013;26: 211-217.

9. Fernández-Ballesteros R, Bustillos A, Santacreu M, Schettini R, Díaz-Veiga P, Huici C. Is older adult care mediated by caregivers' cultural stereotypes? The role of competence and warmth attribution. Clin Interv Ageing. 2016a;11:545-552.

10. Molina MA, Fernández-Ballesteros R. Influence of Context in Cultural Stereotypes Regarding Older Adults. Technical report. Madrid: Universidad Autónoma de Madrid; 2016.

11. Fernández-Ballesteros R. Sistema de Evaluación de Residencias de Ancianos, SERA. (Assessment System for Older Adults Residences). Madrid: INSERSO;1996. Spanish.

12. Moos R, Lemke S. Multiphasic Environmental Assessment Procedure (MEAP). Palo Alto, CA: SAGE;1996.

13. Izal M. Cross-cultural Environmental Assessment. Eur J Psychol Assess. 1992;8(2):118-125.

14. Muthén LK, Muthén BO. Mplus User's Guide. 7th ed. Los Angeles, CA: Muthén \& Muthén;1998-2012.

15. Cohen J. A power primer. Psychol Bull.1992;112:155-159.

16. Fiske ST, Xu J, Cuddy A, Glick P. (Dis)respecting versus (dis)liking: status and interdependence predict ambivalent stereotypes of competence and warmth. J Soc Issues.1999;55:473-491.

17. Fernández-Ballesteros R, Bustillos A, Casal CH, Casado JM. Age discrimination, Eppur si muove (yet it moves). J Am Geriatr Soc. 2016;64(2):453-454.

18. Fernández-Ballesteros R, Olmos R, Santacreu M, et al. Assessing aging stereotypes: personal stereotypes, self-stereotypes and self-perception of aging. Psicothema. 2017;29(4):482-489.

19. Funk LM, Stajduhar KI. Interviewing family caregivers: implications of the caregiving context for the research interview. Qual Health Res. 2009;19(6):859-867.
Clinical Interventions in Aging

\section{Publish your work in this journal}

Clinical Interventions in Aging is an international, peer-reviewed journal focusing on evidence-based reports on the value or lack thereof of treatments intended to prevent or delay the onset of maladaptive correlates of aging in human beings. This journal is indexed on PubMed Central, MedLine,

\section{Dovepress}

CAS, Scopus and the Elsevier Bibliographic databases. The manuscript management system is completely online and includes a very quick and fair peer-review system, which is all easy to use. Visit http://www.dovepress. com/testimonials.php to read real quotes from published authors. 